\title{
El singular, la práctica y la incertidumbre de la
} razón

\author{
Carlos Pereda \\ Universidad Nacional Autónoma de México
}

Llano's work suggests that concepts are mere auxiliaries in the knowledge of individuals and that this knowledge is determined by the claims of some human practical activities. Both suggestions arise some arguments in favour of uncertainty of reason and the need of practical judgement against pure theoretical considerations.

El conocimiento del singular de Carlos Llano Cifuentes constituye un excelente trabajo sobre algunas teorias acerca de lo singular; $y$ algo más, pues nos encontramos también frente a un libro-prólogo de otras investigaciones. Pero vayamos paso a paso.

En primer lugar, se trata, en efecto, de una cuidadosa monografia en gran medida histórica que recorre básicamente cinco aproximaciones al tema: Aristóteles, Santo Tomás, una breve discusión de Wittgenstein y luego, con cierta minucia, se lee a quienes tal vez fueron los dos discípulos más importantes de José Ortega y Gasset: José Gaos y Xavier Zubiri. En todo este recorrido hay muchos detalles dignos de destacar. Me detengo un poco en el tratamiento que dedica Llano a Aristóteles. Llano nos recuerda cómo en el libro VII de la Metafísica, Aristóteles reconstruye la pregunta de sus antecesores por el ser con la pregunta "¿Qué es la sustancia?", distinguiendo entre sustancia primera, que es el individuo determinado por accidentes reales, por ejemplo Sócrates, y la sustancia segunda, que es el universal, por ejemplo hombre. Obsérvese que la ordenación de las sustancias en primera y segunda implica ya cierta polémica con 
Platón y hasta con Sócrates. Además, en relación con cualquier sustancia, Aristóteles distingue lo que Llano llama "sustancias partes", la materia y la forma, que conjuntamente forman la sustancia completa. Aristóteles aborda el concepto de la sustancia de dos maneras. Por un lado, por la vía del lenguaje se descubre que la sustancia es sujeto: el sujeto que soporta y unifica los diversos predicados; el problema radica en que, entonces, parecería que nada podemos decir de la sustancia más que lo que dicen sus predicados. Pero ¿esto es así?

A mí nunca me ha quedado claro si Aristóteles piensa que a) el conocimiento de la sustancia primera se agota en sus predicados; o b) los predicados son meros auxiliares en el conocimiento de la sustancia primera. Sea cual fuere la opción defendida por Aristóteles, (b) es la opción verdadera. Y me inclino a pensar que con frecuencia ésta podría ser la opinión de Aristóteles teniendo en cuenta precisamente la segunda vía con que Aristóteles enfrenta el problema de la sustancia: si por la vía del lenguaje llegamos a la sustancia como sujeto, por la vía de la naturaleza llegamos a la sustancia como inalterable. En este sentido, me gustaría pensar, en contra de Llano, y con el sarcasmo de Russell, que la sustancia es, en verdad, 'una percha de la que cuelgan los predicados", pues a menudo a pesar de que nuestros predicados sean falsos podemos igualmente acceder a la sustancia primera, a 'la percha". Todos me entienden a qué sustancia primera aludo cuando uso la expresión "sacro imperio romano", incluso aunque el régimen político a que me refiero no haya sido ni sacro, ni imperio, ni romano. Pero si esto es el caso, lo único que podemos conocer de la sustancia no son los predicados que le corresponden; también podemos conocer la existencia, que no es un predicado más. Kripke ha respaldado en estas comprobaciones cierto sobrecargado retorno a la metafisica.

Podria seguir de este modo discutiendo a partir de las interesantes elaboraciones que va haciendo Llano cuando estudia a Santo Tomás, a Gaos, a Zubiri... Pero ya he dicho que el libro es algo más que una monografia histórica, es todo él un libro-prólogo. 
En efecto, la introducción no sólo prologa el libro sino que también anuncia posibles caminos para continuarlo. Debo confesarlo: la introducción me resultó la parte más original y sugestiva del trabajo $y$, por eso, quiero detenerme un poco en ella. Llano comienza introduciendo cierta paradoja que se nos presenta apenas pretendemos el conocimiento del singular: tiene razón Aristóteles, la sustancia primera es lo singular; no obstante, cada vez que intentamos aproximarnos a la individualidad de la sustancia primera se necesita la ayuda de las sustancias segundas, de conceptos, de universales. Algún platónico opinará, entonces, que nos olvidemos de los particulares y nos retiremos al mundo de las ideas universales. Pero, como indica Llano, la práctica bloquea esta estrategia: cualquier práctica requiere de singulares, se hace con y para singulares. De ahí que a partir de cierto Aristóteles muchos hayan llegado a sospechar que al conocimiento de lo universal y al conocimiento del singular deben corresponder dos facultades diferentes. Llano señala con razón:

Nosotros pensamos que es uno y el mismo entendimiento quien conoce lo universal mediante la ciencia, mientras mediante la prudencia puede habérseles con lo singular; $y$ sabemos que la ciencia y la prudencia no son dos entendimientos, sino dos hábitos de la misma y única facultad intelectual humana. La articulación y nexo entre ciencia general y especulativa, y prudencia particular y práctica ni son sencillos, ni están temáticamente resueltos (p. 15).

No obstante, las dificultades que presenta este nexo, unas páginas más adelante Llano se arriesga a ciertas consideraciones al respecto. Por lo pronto, indica Llano:

El entendimiento especulativo tiene siempre un momento, siquiera minimo, del práctico. Si se le pregunta por ese momento, habría que contestar sin duda que el entendimiento especulativo tiene un importante punto limitrofe con el entendimiento práctico precisamente en el momento de su inicio (pp. 22-23). 
Pienso que Llano es en este momento demasiado tímido. La ciencia moderna no ha sido nunca contemplativa (no hay nada menos contemplativo que la práctica de un experimento), y en la práctica cientifica (porque la ciencia es, ante todo, un conjunto de prácticas) constantemente nuestra capacidad de juicio, o si se prefiere, nuestra phronesis, la prudencia, juega un papel decisivo. A cada paso, el científico tiene que decidirse, ir por un camino y abandonar otros, explorar cierta descripción de un objeto desechando todos los demás, afiliarse a un paradigma y a ciertos enfoques, al menos como punto de partida; y eliminar, por el momento al menos, sus alternativas. Y a su vez, la prudencia a menudo tampoco puede eliminar el conocimiento teórico: por supuesto, hay prácticas como la carpintería o andar en bicicleta cuyos presupuestos teóricos son nulos o casi nulos. Sin embargo, hay otros casos: las prácticas de la medicina o de la navegación o de la administración de empresas necesitan de teorías. Pero estas observaciones, creo, de ningún modo van en contra de lo que básicamente busca defender Llano. Al respecto, él mismo aclara:

toda ciencia tiene una inflexión prudencial, que nos señala lo que es conveniente indagar, así como toda prudencia ha de incluir un denso coeficiente especulativo, porque también ella, aun siendo un saber del singular, se encuentra regida por las mismas reglas generales que marcan el dominio de la realidad singularizada (p. 2).

Expresando este pensamiento con otras palabras: no hay razón sin incertidumbre, sin la contingencia de las situaciones particulares; pero una razón incierta es todavía una razón: es nuestra razón humana. 
Copyright of Tópicos. Revista de Filosofía is the property of Universidad Panamericana and its content may not be copied or emailed to multiple sites or posted to a listserv without the copyright holder's express written permission. However, users may print, download, or email articles for individual use. 